\title{
Evaluating a Sick Child after Travel to Developing Countries
}

\author{
Michael A. Tolle, MD, MPH
}

Every year, millions of children travel internationally with their families, many to developing countries. Although the vast majority experience uneventful travel and return home well, it is not uncommon for children to present as ill during or after travel. Although the majority of travel-associated illness is mild and self-limited, serious conditions regularly occur. Almost all life-threatening conditions after travel present with fever, and malaria is the most important of these to rapidly exclude. Gastrointestinal symptoms are common after travel in the developing world, and most diarrhea in child travelers has a bacterial source. Children who have a rash in association with fever or who appear ill should receive a priority work-up focused on ruling out serious conditions. Many children traveling internationally experience respiratory illness during or shortly after travel, mainly common upper respiratory infections, yet serious conditions, such as tuberculosis, may occur. Eosinophilia is common in the returned pediatric traveler, particularly those with prolonged stays in the tropics. Not all eosinophilia is caused by parasitic infection; drug reactions, asthma, and other allergic conditions are also common causes. With a focus first on ruling out life-threatening disease and subsequently on an informed and efficient path to diagnosis and treatment, clinicians may confidently provide care for this challenging group of patients. (J Am Board Fam Med 2010;23:704-713.)

Keywords: Travel Medicine, Tropical Medicine, Pediatrics, Family Health, International Health

Every year, millions of children travel internationally with their families, many to developing countries. ${ }^{1}$ Although the vast majority experience uneventful travel and return home well, it is not uncommon for children to present as ill during or after travel. ${ }^{2}$ Although the majority of travel-associated illness is mild and self-limited, serious conditions regularly occur. ${ }^{3}$ Because many health care practitioners in industrialized countries may be unfamiliar with conditions uncommon in their practice setting, this article seeks to review common presentations of the ill child after travel and offer an organized approach to their evaluation.

This article was externally peer reviewed.

Submitted 4 December 2009; revised 8 June 2010; accepted 14 June 2010.

From the Department of Pediatrics, Baylor College of Medicine, Houston, TX.

Funding: none.

Conflict of interest: none declared.

Corresponding author: Michael A. Tolle, MD, MPH, Department of Pediatrics, Baylor College of Medicine, 6701 Fannin Street, CC1210, Houston, TX 77030 (E-mail: tolle@bcm.edu).

\section{General Approach}

A general approach to the child who presents as ill after international travel is outlined in Table 1. An appreciation of the nuances of common pediatric presentations after travel greatly informs this approach.

\section{Common Presentations}

Fever

Almost all life-threatening conditions after travel present with fever. ${ }^{4}$ Although malaria is the most important of these to rapidly exclude, other potentially serious tropical infections that commonly cause fever after travel include dengue, typhoid, rickettsioses, and leptospirosis; rarely, other serious infections are encountered. ${ }^{2,4}$

Imported pediatric malaria is not uncommon. ${ }^{5}$ Children account for $15 \%$ to $20 \%$ of the several thousand annual cases of imported malaria in industrialized countries, ${ }^{5}$ and incidence is highest in children who have traveled with caregivers visiting friends and relatives (travelers known as VFRs). ${ }^{5}$ Although Plasmodium falciparum is the most dan- 


\begin{tabular}{|c|c|}
\hline Travel history & $\begin{array}{l}\text { Often, a given condition is found only in a particular geographic region or has a specific } \\
\text { incubation period. For example, a febrile child who presents } 3 \text { days after returning } \\
\text { from a week in Rio de Janeiro during Carnival has a low likelihood of having malaria } \\
\text { (low-risk setting, lower end of the incubation period) but a reasonable chance of } \\
\text { having dengue (high-risk setting, correct incubation period). }\end{array}$ \\
\hline Physical examination & $\begin{array}{l}\text { Focuses on signs associated with tropical illness, such as splenomegaly (malaria, typhoid) } \\
\text { or rash (dengue). }\end{array}$ \\
\hline \multicolumn{2}{|l|}{ Differential diagnosis } \\
\hline Associated with travel & Conditions tropical in nature, or otherwise nonendemic to home region \\
\hline Not associated with travel & $\begin{array}{l}\text { As an example, a child who develops fever, rash, and hypotension a few days after return } \\
\text { from a week-long holiday in El Salvador could have dengue acquired in El Salvador, } \\
\text { among other diagnoses, but could also have rickettsial disease, adenovirus, or other } \\
\text { illness acquired at home before travel }\end{array}$ \\
\hline & $\begin{array}{l}\text { A commonly used rule of thumb is the longer from travel symptoms present, the less } \\
\text { likely they are to be associated with travel, although some conditions, such as vivax } \\
\text { malaria, may present months after return from the tropics }\end{array}$ \\
\hline \multirow[t]{2}{*}{ Diagnostic evaluation } & Driven by the differential diagnosis \\
\hline & $\begin{array}{l}\text { Gives clues (thrombocytopenia plus hyperbilirubinemia commonly seen with malaria; } \\
\text { leukopenia with typhoid, dengue, and other infections) or looks for specific etiologies } \\
\text { themselves (malaria smear, Entamoeba bistolytica antigen) }\end{array}$ \\
\hline Treatment and/or referral & Allow for definitive resolution of the presenting issue \\
\hline
\end{tabular}

gerous malarial strain, any malaria in a nonimmune child (most travelers) is serious ${ }^{6}$; malaria caused by Plasmodium vivax, for example, may also be associated with severe malaria. ${ }^{7,8}$ Particularly in infants and smaller children, malaria may present with protean manifestations, including predominantly gastrointestinal symptoms such as abdominal pain or vomiting, making diagnosis challenging unless a high index of suspicion exists. ${ }^{6}$

Whether or not the child received antimalarial chemoprophylaxis is an important historic detail, but of greatest importance is whether or not the child was exposed to malaria; malaria may develop even when prophylaxis has been properly taken. ${ }^{6}$ Any ill, febrile child who has traveled in a malariaendemic zone (see map at www.cdc.gov/malaria/ risk_map/) in the year before presentation could have malaria. ${ }^{9}$ The risk of severe malaria is higher for those who present during the first month after travel because $P$. falciparum's incubation period is typically 10 to 30 days (range, 7-90 days), ${ }^{4}$ and for those who have traveled to sub-Saharan Africa (where $P$. falciparum is the most common malarial strain). ${ }^{5}$

Incubation periods (Table 2) give critical clues to the etiology of fever after travel. ${ }^{1}$ For example, in much of the tropics, areas endemic for malaria and dengue overlap. Fever that develops within 7 days of entering an endemic area should not be caused by malaria, whereas fever developing more than 2 weeks after leaving an endemic area should not be because of dengue. ${ }^{10}$

Initial investigations for a febrile child without a localizing source of infection vary based on the individual history, but will probably include a complete blood count, liver function tests, urinalysis, blood culture, and peripheral blood smears for malaria. ${ }^{11,12}$ Additional testing may include cultures of stool and urine, chest radiography, and specific serologic assays such as those for dengue, rickettsiae, schistosomes, and Leptospira. ${ }^{11,12}$

The proper management of malaria depends on the diagnosis being swift and reliable. Alternatives for malaria diagnosis exist. Traditionally, malaria has been diagnosed with blood smears; a minimum of 3 sets must be performed before malaria can be tentatively ruled out in a child who has a history of possible malaria exposure and clinical signs and symptoms potentially consistent with the disease. ${ }^{6}$ Yet, although serial blood smears have very high specificity, ${ }^{13}$ their sensitivity is relatively $\operatorname{low}^{14}$ and quite dependent on the experience level of their interpreter, which may be limited in many nonendemic settings. ${ }^{9}$ Rapid diagnostic tests (RDTs) based on the detection of species-specific, histidine-rich proteins or lactate dehydrogenase exist and will readily both diagnose malaria and differentiate between falciparum and nonfalciparum infections. ${ }^{15,16}$ In field and clinical trials, several of these compared well with blood smear analysis in 
Table 2. Incubation Periods for Selected Infections Responsible for Fever in Children Who Have Returned from the Tropics

Incubation Period

(days) Infections

\begin{tabular}{|c|c|}
\hline \multirow[t]{7}{*}{$\leq 14$} & Dengue \\
\hline & Malaria* \\
\hline & Yellow fever \\
\hline & Chikungunya \\
\hline & Typhoid fever ${ }^{\dagger}$ \\
\hline & Rickettsial infections $^{\ddagger}$ \\
\hline & Leptospirosis $\$$ \\
\hline \multirow[t]{7}{*}{15 to 30} & Malaria* \\
\hline & Typhoid fever ${ }^{\ddagger}$ \\
\hline & Leptospirosis $\$$ \\
\hline & Hepatitis $\mathrm{A}$ and $\mathrm{E}^{\|}$ \\
\hline & Visceral leishmaniasis \\
\hline & Acute schistosomiasis (Katayama fever) ${ }^{\mathbb{I}}$ \\
\hline & Tuberculosis \\
\hline \multirow[t]{5}{*}{$>30$} & Malaria* \\
\hline & Hepatitis A and $\mathrm{E}^{\|}$ \\
\hline & Acute schistosomiasis (Katayama fever) ${ }^{\mathbb{I}}$ \\
\hline & Visceral leishmaniasis \\
\hline & Tuberculosis \\
\hline
\end{tabular}

*Most Plasmodium falciparum infections have an incubation period of 7 to 30 days (average, $\sim 10$ days); Plasmodium vivax and Plasmodium ovale may present late, months or even years (rarely) after infection.

${ }^{\dagger}$ Average incubation period of typhoid is 14 days, but can vary from $<7$ to $>21$ days. Incubation periods of $>30$ days are quite rare. $^{3}$

${ }^{\ddagger}$ Most rickettsial infections have incubation periods of $<14$ days. $^{3}$

${ }^{\S}$ Leptospirosis has an average incubation period of 1 to 2 weeks; rarely, leptospirosis may present $>14$ days after infection.

"Hepatitis A and E have an incubation period of 2 to 6 weeks; jaundice is usually seen.

${ }^{I}$ Acute schistosomiasis typically presents $>4$ weeks after exposure to fresh water in the tropics.

the detection of $P$. falciparum..$^{15,16}$ One recently reported randomized clinical trial demonstrated $95.4 \%$ sensitivity and $95.9 \%$ specificity in the detection of malaria using RDTs. ${ }^{16}$ Molecular diagnostics (such as polymerase chain reaction) are particularly useful where malaria incidence is low and false-negative smears or RDT results are more likely to be accepted as valid (as in most industrialized settings where children ill after travel are evaluated). ${ }^{17}$ Even when initial malarial tests are negative, children who have a history of malaria exposure and suggestive symptoms should be approached as if they have malaria until an alternative diagnosis is made. ${ }^{6,12}$
Specific management of malaria depends on whether the case is severe or uncomplicated and on the particular or suspected malarial strain (particularly whether or not the strain is $P$. falciparum). ${ }^{5,9,18,19}$ Most countries have guidelines for malaria management, ${ }^{9,19}$ as does the World Health Organization. ${ }^{18}$ Unless a practitioner has experience with malaria diagnosis and management, early consultation with an infectious disease or tropical medicine specialist is advisable, and most national authorities have a service comparable to the Centers for Disease Control and Prevention in the United States, which operates a Malaria Hotline for assistance with suspected or confirmed malaria cases (1-770-488-7788).

A major public health threat in the tropics, dengue has become the most common diagnosis in febrile travelers returned from all tropical regions except Africa. ${ }^{10}$ Dengue has a short incubation period and generally results in self-limited illness, although as many as 250,000 cases of severe dengue (hemorrhagic and shock syndrome forms) occur annually, including cases in returned travelers. ${ }^{10}$ Dengue risk for travelers is sometimes characterized as the "opposite" of that for malaria: most commonly transmitted in urban areas during the daytime (where and when its principal vector, Aedes aegypti, lives and feeds) whereas malaria risks are generally higher from dusk to dawn (when its Anopheles spp. vector feeds) and in rural areas. ${ }^{20}$

A clinical diagnosis, dengue presents after exposure in an endemic area with fever, uncomfortable constitutional symptoms and, often, a characteristic maculopapular rash (Figure 1), which may be less apparent in children who have darker complexions. ${ }^{21}$ Leukopenia and thrombocytopenia are common laboratory findings, and useful serologies and rapid diagnostic tests may be available in some settings. ${ }^{22}$

\section{Care of Patients Varies by Degree of Dengue Severity}

Dengue hemorrhagic or shock syndrome is rare with primary dengue infection (the case with most travelers). ${ }^{10,21}$ Nonsevere dengue is self-limited and care is supportive, whereas severe dengue requires hospitalization and intensive management focused on early recognition and treatment of shock. ${ }^{21}$ Development of severe dengue is heralded by hemoconcentration (increasing hemoglobin); thickening of the gallbladder wall has been shown to predict the development of vascular permeability 
Figure 1. Maculopapular rash with diffuse petechiae and areas of bruising associated with dengue hemorrhagic fever. Photo courtesy of the Emerging Infectious Diseases journal. Reprinted from http://www.cdc.gov/EID/content/14/8/1329-G.htm.

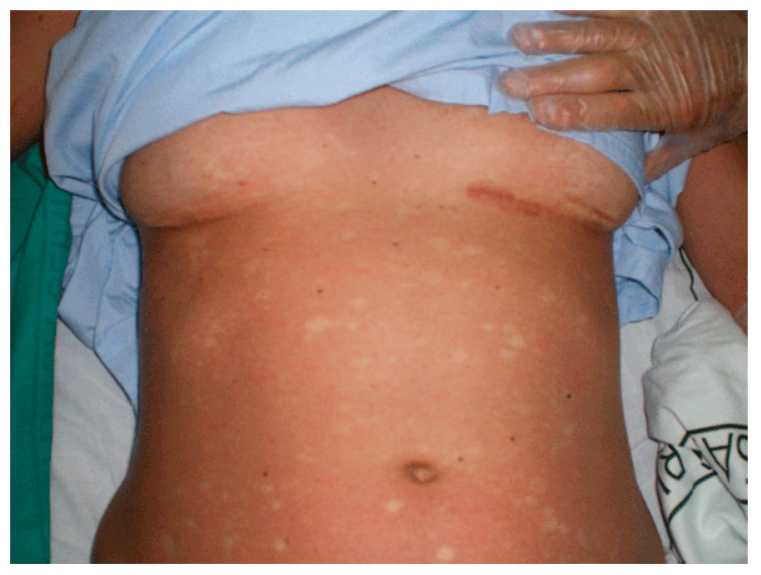

(the hallmark of severe dengue ${ }^{21}$ ) in children who have dengue. ${ }^{23}$

The Chikungunya virus (also transmitted by Aedes spp mosquitoes) overlaps epidemiologically with dengue and causes a febrile arthralgia syndrome. Millions of cases of chikungunya have been seen in Africa, the Indian Ocean basin, the Indian subcontinent, and Southeast Asia since 2005, including thousands in returned travelers. ${ }^{24}$ The incubation period is similar to dengue and a similar rash may be present, but severe disease is rare, particularly in children. ${ }^{25}$ Treatment is symptomatic, and illness caused by chikungunya is usually self-limited but substantial joint pain may persist. ${ }^{26}$

Yellow fever is a serious arboviral disease with a high fatality rate, yet is very rare in travelers because of the availability of an effective vaccine. ${ }^{27}$ Other arboviral illnesses may occur, but are rarely reported in travelers. ${ }^{22}$

Virtually indistinguishable clinically, ${ }^{11}$ typhoid and paratyphoid (enteric fever) are caused by fecaloral transmission of Salmonella typhi and Salmonella paratyphi, respectively. Risk is higher for VFRs than for traditional tourists and for those who have traveled to the Indian subcontinent, where incidence is highest. ${ }^{12}$ Symptoms include fever and abdominal pain, myalgias and arthralgias, nausea and vomiting, and occasionally diarrhea. ${ }^{28}$ Some patients may exhibit a characteristic, if uncommon, "stepladder" fever pattern, with febrile temperature progressively increasing over time. ${ }^{28}$ Relative bradycardia is a classic associated sign (although also seen with other tropical infections), as are splenomegaly, rose spots, and, occasionally, confusion. ${ }^{28}$

Laboratory studies often show a normal or decreased white blood cell count, and liver enzymes are usually elevated. Diagnosis of typhoid occurs via culture. Bone marrow cultures are most sensitive $(80 \%$ to $95 \%)$, whereas blood cultures and stool cultures show variable sensitivity (blood cultures are $70 \%$ sensitive during the first week and $30 \%$ sensitive during the second week; stool cultures are more sensitive as the disease progresses ${ }^{3}$ ).

Although $10 \%$ to $15 \%$ of patients will have complications, including life-threatening gastrointestinal bleeding or perforation, complications are more frequent in younger patients and those who have been ill more than 14 days. ${ }^{12}$

Antibiotic treatment depends on the region of the world where infection was acquired, with Latin American and Caribbean strains presumed to be fully sensitive (amoxicillin, trimethoprim-sulfamethoxazole, quinolones); South Asian strains may be multidrug resistant, including to quinolones, requiring azithromycin or cefixime. ${ }^{12,28-30}$ Severe illness should, of course, be treated in a hospital with parenteral antibiotics.

Rickettsial infections should be considered in the differential diagnosis of the febrile returned child, particularly African tick-bite fever, caused by Rickettsia africae and increasingly common in recent years, particularly in southern Africa, including popular game parks. ${ }^{11}$ African tick-bite fever classically presents with a primary eschar at the site of the tick bite, followed by a flu-like illness with generalized rash. ${ }^{11}$ Diagnosis of rickettsial illness can be made by specific serology; treatment for adults and children is with doxycycline. ${ }^{31}$

Not restricted to the tropics, leptospirosis acquisition by travelers usually occurs through recreational exposure to water or soil contaminated with infected animal urine, with outbreaks more common after heavy rainfall. ${ }^{12}$ Leptospirosis should be considered in the febrile returned child who is systemically ill and who has tested negative for malaria, particularly if characteristic features such as conjunctival inflammation are present. Although serologic diagnosis is available, it may be of low yield. ${ }^{12}$ Severe leptospirosis may progress to jaundice, renal failure, and hemorrhage, and case fatality rates can be high. ${ }^{12}$ Children should be treated with ampicillin or doxycycline, and severe disease 
should be treated with intravenous ceftriaxone or penicillin G. ${ }^{12}$

\section{Gastrointestinal Symptoms}

Although generally not possessing the serious nature that fever may, gastrointestinal symptoms are nonetheless common after travel in the developing world.

Most traveler's diarrhea (TD) in children is caused by bacteria, but in children younger than age 2, viral etiologies (norovirus, rotavirus if not immunized) may be more common, as may be atypical and/or prolonged episodes of TD. ${ }^{32,33} \mathrm{TD}$ is usually self-limited and often warrants simple observation. Azithromycin is the treatment of choice for most bacterial etiologies; $10 \mathrm{mg} / \mathrm{kg}$ once daily for 3 days is a common regimen. ${ }^{34}$ Helpful laboratory studies include stool cultures, giardia antigen, hemoccult, and fecal leukocytes; when red and white blood cells are both absent from the stool, the negative predictive value to exclude invasive organisms exceeds $95 \% .^{3}$

Persistent diarrhea (present $>2$ weeks) is more likely to have a protozoal source (such as Giardia lamblia or Cryptosporidium). ${ }^{32}$ Stool samples for ova and parasite analysis should be performed to exclude parasitic sources. Even a single sample has utility; data from studies of serial stool sample analysis show $>90 \%$ of parasites are detected in the first sample submitted. ${ }^{35}$ Testing for Giardia antigen can increase the yield in the diagnosis of this common parasitic cause of persistent diarrhea and may need to be tested repeatedly. ${ }^{36}$ Likewise, special stains of stool for Cryptosporidium and Cyclospora are often necessary to identify these organisms, which in some series have been shown to be relatively common causes of persistent diarrhea in returned travelers. ${ }^{37}$ When there is a history of antibiotic exposure, testing for Clostridium difficile may yield a diagnosis. ${ }^{38}$ As mentioned above, infants and young children may experience prolonged episodes of diarrhea when infected with bacterial organisms that commonly cause acute, self-limited diarrhea in older individuals; for this age group, stool cultures may be useful in the evaluation of persistent diarrhea. ${ }^{32}$

When diarrhea persists and repeated investigations for infection are negative, noninfectious causes, such as secondary lactose intolerance after infection, should be considered. Irritable bowel syndrome after infection is also common after an episode of TD, as is the "unmasking" of autoimmune diseases, such as inflammatory bowel disease or celiac sprue. ${ }^{33}$

Tropical sprue is a rare cause of persistent diarrhea that has malabsorptive features; most commonly seen after travel to South Asia, its incidence is declining. ${ }^{33}$ It generally responds to a course of broad-spectrum antibiotics. ${ }^{39}$ Helminthic infections (roundworms) are unlikely in traveling children, but may be more common in children who have had prolonged stays in the tropics or children traveling with VFRs; with heavy infestations there may be symptoms. ${ }^{3}$

Uncommonly, children may also present with jaundice after travel in the developing world, and this may herald serious illness. ${ }^{3}$ Febrile jaundice should prompt a brisk and thorough assessment for life-threatening disease. ${ }^{3}$ Although viral hepatitis (primarily caused by hepatitis A) can also present with fever, symptomatic hepatitis A infection in traveling children is uncommon. ${ }^{40}$ Hepatitis $\mathrm{E}$ is a common cause of acute hepatitis in the developing world, shares a common fecal-oral route of transmission with hepatitis A, and should be considered when hepatitis A testing is negative. ${ }^{41}$

Figure 2. Cutaneous larva migrans. A and B: Typical elevated lesion caused by the migrating parasite on the plantar surface of the foot. C: Ulcerative lesion at site of origin on the lateral side of the foot. Photo courtesy of the Emerging Infectious Diseases journal. Reprinted from http://www.cdc.gov/eid/content/15/11/1856-F.htm.
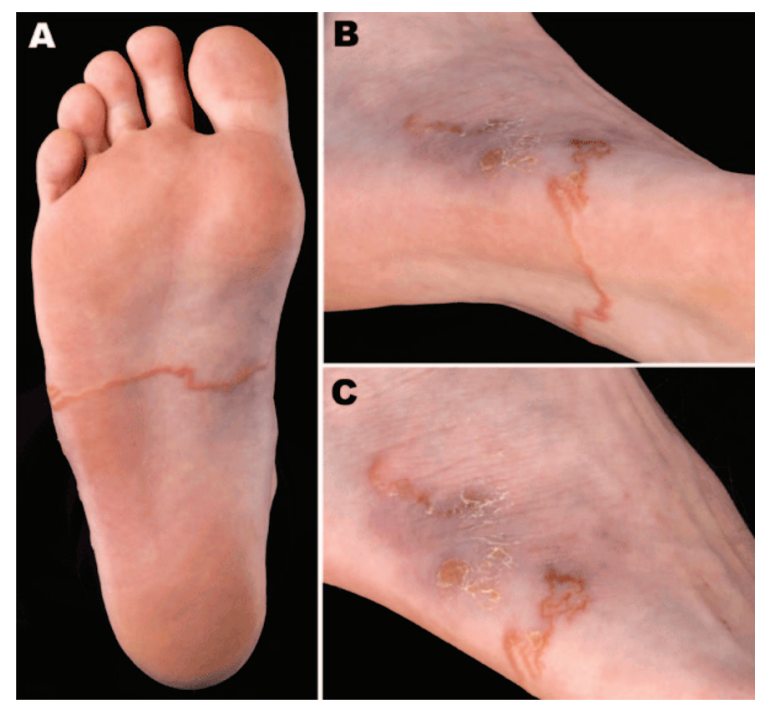


\section{Dermatologic Symptoms}

Skin conditions are common after travel to the tropics, and in large, retrospective reviews have been noted to occur disproportionately after travel to the Caribbean or Central or South America., 2,42 As described above, many tropical infections, such as dengue, present with skin findings, as do many cosmopolitan infections, such as measles, meningococcemia, and rickettsioses. Rash-particularly if petechial or hemorrhagic-in association with fever or an child who appears ill should receive a priority workup focused on ruling out serious conditions. ${ }^{11,12,21}$

Fortunately, serious underlying disease is rare in children who present with skin conditions after travel. ${ }^{42}$ In a review of infants to children aged 17 years who presented to a large, global network of tropical and travel medicine clinics (GeoSentinel), the 5 most common skin conditions after travel were cutaneous larva migrans, dog bites, insect bites (including superinfected), cutaneous leishmaniasis, and superficial skin abscesses. ${ }^{42}$
Diagnosis of common tropical skin conditions tends to be straightforward; clinical diagnoses, aided by knowledge of geographical disease trends, are the rule. Dog bites, insect bites, and superficial skin abscesses are clear diagnoses, whereas urticaria suggests allergic or parasitic exposure, with schistosomiasis and strongyloides being common causes of urticaria among the latter group. ${ }^{3}$

Cutaneous leishmaniasis in travelers most commonly presents several weeks after travel to Central and South America as an ulcerated skin lesion (having originated as a papulonodular lesion at the site of a sand fly bite) surrounded by a raised, indurated border $^{42,43}$; it is also a common condition in the Middle East, Iran, and Afghanistan. ${ }^{43}$

Cutaneous larva migrans occurs after exposure of bare skin to sand, and, not surprisingly, tends to follow tropical beach holidays. ${ }^{44}$ An intensely itchy, migratory rash (Figure 2), usually around the foot or ankle, but possible anywhere skin contacted sand (such as the back), represents subcutaneous movement of the larval stage of the dog hookworm. ${ }^{44}$

Table 3. Management of Common Skin Conditions Presenting after Travel to Developing Countries

\begin{tabular}{|c|c|c|}
\hline Condition & Presentation & Treatment/Management \\
\hline Cutaneous larva migrans ${ }^{44}$ & $\begin{array}{l}\text { Although rash will heal spontaneously within } \\
\text { a few weeks, the unpleasant cosmetic } \\
\text { appearance and substantial itching usually } \\
\text { dictate treatment }\end{array}$ & $\begin{array}{l}\text { Albendazole ( } 400 \mathrm{mg} \text { single dose) } \\
\text { Ivermectin ( } 200 \mathrm{mcg} / \mathrm{kg} \text { single dose) }\end{array}$ \\
\hline Dog bites/minor trauma & & $\begin{array}{l}\text { Management of potential rabies after exposure, } \\
\text { as indicated } \\
\text { Topical antibiotic, as indicated } \\
\text { Oral antibiotic if cellulitis is present }\end{array}$ \\
\hline Superficial skin infections & & Topical vs oral antibiotic, as indicated \\
\hline Cutaneous Leishmaniasis ${ }^{43,46}$ & $\begin{array}{l}\text { Can have severe sequelae, including } \\
\text { destructive mucosal disease with some } \\
\text { New World strains }\end{array}$ & $\begin{array}{l}\text { Some therapeutic agents can be difficult to } \\
\text { obtain in some industrialized settings } \\
\text { Although topical paromomycin may be } \\
\text { effective against some Leishmania strains } \\
\text { with very low potential for mucosal spread, } \\
\text { prolonged parenteral therapies may be } \\
\text { necessary } \\
\text { Consider referral to an expert in tropical } \\
\text { medicine/infectious diseases }\end{array}$ \\
\hline Myiasis $^{45}$ & Bot fly (Central and South America) & $\begin{array}{l}\text { Place petroleum jelly over the larva's } \\
\text { communication to the skin. Larva will then } \\
\text { protrude from the lesion and can be } \\
\text { removed with forceps } \\
\text { Bot fly larvae anatomy make simple removal } \\
\text { more difficult than for Tumbu fly, yet the } \\
\text { above technique may be attempted. Often } \\
\text { lidocaine infiltration followed by removal } \\
\text { through incision is necessary }\end{array}$ \\
\hline Scabies $^{46}$ & & $\begin{array}{l}\text { Usually responds to topical permethrin }(5 \%) \\
\text { Lindane should be avoided in young children } \\
\text { Oral ivermectin ( } 200 \mathrm{mcg} / \mathrm{kg} \text { single dose) is an } \\
\text { alternative therapy }\end{array}$ \\
\hline
\end{tabular}


Myiasis is another common skin condition imported from the tropics, occurring when a fly larva infests skin, creating a painful, boil-like lesion. Tumbu fly myiasis is seen in travelers returning from tropical Africa whose clothing was contaminated with fly eggs, usually while hanging on a washing line; ironing clothes with a hot iron after line drying may be preventive. ${ }^{45}$ Bot fly myiasis presents in travelers returning from Central and South America; unlike the Tumbu fly, the bot fly deposits its eggs directly on the skin. ${ }^{45}$ Management of myiasis and other skin conditions presenting commonly after tropical travel is detailed in Table 3.

\section{Respiratory Symptoms}

As many as $25 \%$ of children traveling internationally may experience a respiratory illness during or shortly after travel, mainly common upper respiratory infections such as pharyngitis, sinusitis, and otitis media; air travel alone is a risk factor for these conditions. ${ }^{1}$ The child who presents with flu-like illness outside of influenza season could still have influenza because influenza circulates year-round in the tropics, and in "summer" (by "home country" definition) in the opposite hemisphere. Although exotic pulmonary infections are reasonably uncommon in travelers, travel histories and regional disease trends are very important when respiratory symptoms are present, as is demonstrated by reports of acute histoplasmosis (headache, fever, cough, myalgias) in a large group of children who were visiting a cave site in Costa Rica ${ }^{47}$; melioidosis (usually pneumonia) in returned travelers from Southeast Asia and northern Australia ${ }^{48}$; and, most recently, H1N1 influenza in children who had recently visited Mexico. ${ }^{49}$

Active pulmonary tuberculosis (TB) in returning pediatric travelers is rare, and, if present, should be associated with chest film findings. ${ }^{3}$ All children who have potentially been exposed to TB during travel (known exposure; prolonged travel in developing countries; and, in some settings, travel with VFRs $^{3}$ ) should be screened for latent TB with placement of purified protein derivative. This is particularly important for infants and young children because severe forms of TB are more common in children younger than 5 years of age (although rates are lower in those who have received Bacille Calmette-Guérin immunization).

\section{Eosinophilia}

Eosinophilia (absolute eosinophil count $>500 / \mathrm{uL}$ ) is common in the returned pediatric traveler, particularly those who stayed in the tropics longer than 3 months $(10 \%))^{3}$ Not all eosinophilia is caused by parasitic infection; drug reactions, asthma, and other allergic conditions are also common causes, although high absolute eosinophil counts $(>1,000)$ in the returned traveler are predictive of parasitic infection. ${ }^{3}$

Table 4. Evaluation of Eosinophilia Presenting after Travel to Developing Countries

\begin{tabular}{|c|c|}
\hline $\begin{array}{l}\text { Exclude nonparasitic causes of } \\
\text { eosinophilia }\end{array}$ & $\begin{array}{l}\text { Drug reaction, asthma, and urticaria; these are often apparent from history and } \\
\text { during examination }{ }^{3}\end{array}$ \\
\hline Initial work-up & $\begin{array}{l}\text { Stool samples for ova and parasites: at least } 3 \text { samples obtained from } 3 \\
\text { different days } \\
\text { Should detect common parasitic causes, such as Ascaris and hookworm, and } \\
\text { may detect Strongyloides and schistosomiasis, as well }{ }^{52}\end{array}$ \\
\hline $\begin{array}{l}\text { Serologies (per clinical and epidemiologic } \\
\text { likelihood) }\end{array}$ & $\begin{array}{l}\text { Often necessary for diagnosis of strongyloidiasis and schistsomiasis, and other, } \\
\text { more rare parasitic causes of eosinophilia in returned travelers, such as } \\
\text { cysticercosis, echinococcosis, toxocariasis, and trichinellosis, among others } \\
\text { Less useful for filariasis, in which marked eosinophilia is generally present only } \\
\text { in the early stage of infection }\end{array}$ \\
\hline Fresh water exposure & $\begin{array}{l}\text { Serology may not be positive until } 3 \text { months or more after exposure } \\
\text { Specificity } 99 \% \text { for all Schistosoma strains } \\
\text { Sensitivity } 99 \% \text { for S. mansoni, but may be less than } 50 \% \text { for S. japonicum and } \\
\text { S. hematobium }\end{array}$ \\
\hline Management of eosinophilia & $\begin{array}{l}\text { Can be difficult to make a specific parasitic diagnosis } \\
\text { Schistosomiasis or strongly suspected schistosomiasis can be treated with } \\
\text { praziquantel } \\
\text { Often, nonschistosomal eosinophilia will resolve with an empiric } 5 \text { to } 7 \text { day } \\
\text { course of albendazole, reflecting its generally helminthic nature } \\
\text { Consultation with a tropical medicine specialist advised when aspects of } \\
\text { diagnosis and management of eosinophilia are unclear }\end{array}$ \\
\hline
\end{tabular}


Schistosomiasis is a particularly common parasitic cause of eosinophilia after exposure to fresh water in the tropics. ${ }^{50}$ Although acute schistosomiasis (Katyama fever) is a cause of fever and urticaria accompanying eosinophilia, schistosomiasis is more commonly discovered in the returned pediatric traveler as positive serology during the workup of asymptomatic eosinophilia noted some time after return or on request by caregivers for a test after known exposure. ${ }^{51}$ Other common parasitic causes of eosinophilia include geohelminths, particularly hookworm and strongyloides, and filariasis ${ }^{3}$; these are more likely in children returning from travel with VFRs and children emigrating or presenting as refugees from endemic tropical regions. ${ }^{50,51} \mathrm{An}$ approach to the evaluation and management of eosinophilia after travel is detailed in Table 4.

\section{Table 5. SORT Recommendations ${ }^{54}$ for the Evaluation and Treatment of a Child Who Presents as Ill after International Travel}

\begin{tabular}{|c|c|}
\hline Recommendation & $\mathrm{SOR}^{*}$ \\
\hline $\begin{array}{l}\text { Malaria may develop even when antimalarial } \\
\text { prophylaxis has been properly taken. It must } \\
\text { be excluded in any ill, febrile child who has } \\
\text { traveled in a malaria-endemic zone in the year } \\
\text { during presentation. }\end{array}$ & $\mathrm{A}$ \\
\hline $\begin{array}{l}\text { Nonsevere dengue is self-limited and care is } \\
\text { supportive, whereas severe dengue (heralded } \\
\text { by hemoconcentration-rising hematocrit or } \\
\text { thickening of the gallbladder wall on } \\
\text { ultrasound) requires hospitalization and } \\
\text { intensive management focused on early } \\
\text { recognition and treatment of shock. }\end{array}$ & A \\
\hline $\begin{array}{l}\text { Most traveler's diarrhea in children is caused by } \\
\text { bacteria, but in children younger than age } 2 \text {, } \\
\text { viral etiologies may be more common, as may } \\
\text { atypical and/or prolonged episodes of } \\
\text { traveler's diarrhea. }\end{array}$ & B \\
\hline $\begin{array}{l}\text { Noninfectious etiologies should be considered } \\
\text { when diarrhea persists and repeated } \\
\text { investigations for infection are negative. }\end{array}$ & A \\
\hline $\begin{array}{l}\text { An child who appears ill and who has a rash } \\
\text { (particularly if petechial or hemorrhagic) in } \\
\text { association with fever should receive a priority } \\
\text { work-up focused on ruling out serious } \\
\text { conditions. }\end{array}$ & $\mathrm{C}$ \\
\hline $\begin{array}{l}\text { High absolute eosinophil counts }(>1,000) \text { in a } \\
\text { returned pediatric traveler are predictive of } \\
\text { parasitic infection, particularly with stays in } \\
\text { the tropics of more than } 3 \text { months. }\end{array}$ & B \\
\hline
\end{tabular}

*Strength of recommendation (SOR): A, good-quality patientoriented evidence; $\mathrm{B}$, inconsistent or limited-quality patientoriented evidence; C, consensus, usual practice, opinion, disease-oriented evidence, case series.

\section{Conclusion}

Most children travel to developing countries and return home without incident. However, although serious illness during or after travel is uncommon, presentation to a clinician with a health-related concern after travel is not. In the evaluation and treatment of a child presenting with such concerns, clinicians must entertain diagnostic possibilities that would not ordinarily be considered had the child not traveled. With a focus first on ruling out life-threatening disease, such as malaria, and subsequently on an informed and efficient path to diagnosis and treatment, clinicians may confidently provide care for this challenging group of patients. Table 5 reviews Strength of Recommendation suggestions for evaluation and treatment of the child who presents as ill after international travel.

\section{References}

1. Summer A, Stauffer W. Evaluation of the sick child following travel to the tropics. Pediatr Ann 2008;37: 821-6.

2. Freedman DO, Weld LH, Kozarsky PE, et al. Spectrum of disease and relation to place of exposure among ill returned travelers. N Engl J Med 2006; 354:119-30.

3. Nield LS, Stauffer W, Kamat D. Evaluation and management of illness in a child after international travel. Pediatr Emerg Care 2005;21:184-95.

4. Ellis C. The returned traveler. Clin Med 2004;4: 505-9.

5. Ladhani S, Aibara RJ, Riordan FA, et al. Imported malaria in children: a review of clinical studies. Lancet Infect Dis 2007;7:349-57.

6. Stauffer W, Fischer PR. Diagnosis and treatment of malaria in children. Clin Infect Dis 2003;37:1340-8.

7. Tijtra E, Anstey NM, Sugiarto P, et al. Multidrugresistant Plasmodium vivax associated with severe and fatal malaria: a prospective study in Papua, Indonesia. PLoS Med 2008;5:e128.

8. Genton B, D'Acremont V, Rare L, et al. Plasmodium vivax and mixed infections are associated with severe malaria in children: a prospective cohort study in Papua, New Guinea. PLoS Med 2008;5:e127.

9. Griffith KS, Lewis LS, Mali S, Parise ME. Treatment of malaria in the United States-a systematic review. JAMA 2007;297:2264-77.

10. Schwartz E, Weld LH, Wilder-Smith A, et al. Seasonality, annual trends, and characteristics of dengue among ill returned travelers, 1997-2006. Emerg Infect Dis 2008;14:1081-8.

11. Bottieau E, Clerinx J, van der Enden E, et al. Fever after a stay in the tropics: diagnostic predictors of the leading tropical conditions. Medicine 2007;86:18-25. 
12. Cavagnaro CS, Brady K, Siegel C. Fever after international travel. Clin Ped Emerg Med 2008;9:250-7.

13. Parija SC, Dhodapkar R, Elangovan S, Chaya DR. A comparative study of blood smear, QBC and antigen detection for diagnosis of malaria. Indian J Pathol Microbiol 2009;52:200-2.

14. McMorrow ML, Masanja MI, Abdulla SM, Kahigwa $\mathrm{E}$, Kachur SP. Challenges in routine implementation and quality control of rapid diagnostic tests for malaria - Rufiji District, Tanzania. Am J Trop Med Hyg 2008;79:385-90.

15. Moody A. Rapid diagnostic tests for malaria parasites. Clin Microbiol Rev 2002;15:66-78.

16. Reyburn H, Mbakilwa H, Mwangi R, et al. Rapid diagnostic tests compared with malaria microscopy for guiding outpatient treatment of febrile illness in Tanzania: randomized trial. BMJ 2007;334:403-9.

17. Mens P, Spieker N, Omar S, Heijnen M, Schallig H, Kager PA. Is molecular biology the best alternative for diagnosis of malaria to microscopy? A comparison between microscopy, antigen detection and molecular tests in rural Kenya and urban Tanzania. Trop Med Int Health 2007;12:238-43.

18. World Health Organization. Guidelines for the treatment of malaria, second edition. Available at: http://whqlibdoc.who.int/publications/2010/ 9789241547925_eng.pdf. Accessed 4 June 2010.

19. Lalloo DG, Shingadia D, Pasvol G, et al. UK malaria treatment guidelines. Journal of Infection 2007; 54:111-21.

20. Wilder-Smith A, Schwartz E. Dengue in travelers. N Engl J Med 2005;353:924-32.

21. World Health Organization. Dengue, dengue hemorrhagic fever and dengue shock syndrome in the context of the integrated management of childhood illness. 2005. Accessed 4 June 2010. Available at: http://whqlibdoc.who.int/hq/2005/WHO_FCH_CAH_ 05.13_eng.pdf.

22. Gould EA, Solomon T. Pathogenic flaviviruses. Lancet 2008;371:500-9.

23. Colbert JA, Gordon A, Roxelin R, et al. Ultrasound measurement of gallbladder wall thickening as a diagnostic test and prognostic indicator for severe dengue in pediatric patients. Pediatr Infect Dis J 2007; 26:850-2.

24. de Lamballerie X, Leroy E, Charrel RN, Ttsetsarkin K, Higgs S, Gould EA. Chikungunya virus adapts to tiger mosquito via evolutionary convergence: a sign of things to come? Virol J 2008;5:33-6.

25. Pialoux G, Gauzere B, Jaureguiberry S, Strobel M. Chikungunya, an epidemic arbovirus. Lancet Infect Dis 2007;7:319-27.

26. Borgherini G, Poubeau P, Joussaume A, et al. Persistent arthralgia associated with Chikungunya virus: a study of 88 adult patients on Reunion Island. Clin Infect Dis 2008;47:469-75.

27. Barnett ED, Wilder-Smith A, Wilson ME. Yellow fever vaccines and international travelers. Expert Rev Vaccines 2008;7:579-87.

28. Basnyat B, Maskey A, Zimmerman M, Murdoch D. Enteric (typhoid) fever in travelers. Clin Infect Dis 2005;41:1467-72.

29. Frenck RW, Nakhla I, Sultan Y, et al. Azithromycin versus ceftriaxone for the treatment of uncomplicated typhoid fever in children. Clin Infect Dis 2000; 31:1134-8.

30. Cao XT, Kneen R, Nguyen TA, Truong DL, White NJ, Parry CM. A comparative study of olfloxacin and cefexime for treatment of typhoid fever in children. Pediatr Infect Dis J 1999;18:245-8.

31. Botelho-Nevers E, Raoult D. Fever of unknown origin due to rickettsioses Infect Dis Clin North Am 2007;21:997-1011.

32. Ang JY, Mathur A. Traveler's diarrhea: updates for pediatricians. Pediatr Ann 2008;37:814-20.

33. Landzberg BR, Connor BA. Persistent diarrhea in the returning traveler: think beyond persistent infection. Scand J Gastroenterol 2005;40:112-4.

34. Stauffer WM, Konop RJ, Kamat D. Traveling with infants and young children. Part III: travelers' diarrhea. J Travel Med 2002;9:141-50.

35. Branda JA, Lin TY, Rosenberg ES, et al. A rational approach to the stool ova and parasite examination. Clin Infect Dis 2006;42:972-8.

36. Addiss DG, Matthews HM, Stewart JM, et al. Evaluation of a commercially available enzyme-linked immunosorbent assay for Giardia lamblia antigen in stool. J Clin Microbiol 1991;29:1137-42.

37. Goodgame R. Emerging causes of traveler's diarrhea: cryptosporidium, cyclospora, isospora, and microsporidia. Curr Infect Dis Rep 2003;5:66-73.

38. Cheng AC, McDonald JR, Thielman NM. Infectious diarrhea in developed and developing countries. J Clin Gastroenterol 2005;39:757-73.

39. Peetermans WE, Vonck A. Tropical sprue after travel to Tanzania. J Travel Med 2000;7:33-4.

40. Rendi-Wagner P, Korinek M, Mikolasek A, et al. Epidemiology of travel-associated and autochthonous hepatitis A in Austrian children, 1998 to 2005. J Travel Med 2007;14:248-53.

41. Langer BC, Frosner GG. Relative importance of the enterically transmitted human hepatitis viruses type $\mathrm{A}$ and $\mathrm{E}$ as a cause of foreign travel associated hepatitis. Arch Virol Suppl 1996;11:171-9.

42. Lederman ER, Weld LH, Elyazar I, et al. Dermatologic conditions of the returned traveler: an analysis from the GeoSentinel Surveillance Network. Int J Infect Dis 2008;12:593-602.

43. O’Dempsey T. Cutaneous leishmaniasis. In: Gill GV, Beeching NJ (eds). Lecture notes on tropical medicine, 5th ed. Oxford, UK: Blackwell Science; 2004. p. 80-3.

44. Gill G. Cutaneous larva migrans. In: Gill GV, Beeching NJ (eds). Lecture notes on tropical medi- 
cine, 5th ed. Oxford, UK: Blackwell Science; 2004. p. 284-5.

45. Gill G. Myiasis. In: Gill GV, Beeching NJ (eds). Lecture notes on tropical medicine, 5 th ed. Oxford, UK: Blackwell Science; 2004. p. 282-3.

46. Drugs for parasitic infections. Med Lett Drugs Ther 2007;5:e1-15.

47. Lyon GM, Bravo AV, Espino A, et al. Histoplasmosis associated with exploring a bat-inhabited cave in Costa Rica, 1998-1999. Am J Trop Med Hyg 2004; 70:438-42.

48. Currie BJ. Melioidosis: an important cause of pneumonia in residents of and travelers returned from endemic regions. Eur Respir J 2003;22:542-50.

49. Centers for Disease Control and Prevention. Update: Infections with a swine-origin influenza A (H1N1) Virus-United States and other countries, April 28, 2009. MMWR Morb Mortal Wkly Rep 2009;58:431-3.
50. Carranza-Rodriguez C, Pardo-Lledias J, MuroAlvarez A, et al. Cryptic parasite infection in recent West African immigrants with relative eosinophilia. Clin Infect Dis 2008;46:48-50.

51. Bierman W, Wetsteyn J, van Gool T. Presentation and diagnosis of imported schistosomiasis: relevance of eosinophilia, microscopy for ova, and serology. J Travel Med 2005;12:9-13.

52. Meltzer E, Percik R, Shatzkes J, et al. Eosinophilia among returned travelers: a practical approach. Am J Trop Med Hyg 2008;78:702-9.

53. Wyatt G. Filariasis and onchocerciasis. In: Gill GV, Beeching NJ (eds). Lecture notes on tropical medicine, 5th ed. Oxford, UK: Blackwell Science; 2004. p. 112-9.

54. Ebell MH, Siwek J, Weiss BD, et al. Strength of Recommendation Taxonomy (SORT): a patientcentered approach to grading evidence in the medical literature. J Am Board Fam Pract 2004;17:59-67. 